Review Article

\title{
Taxonomic and evolutionary analysis of Zaprionus indianus and its colonization of Palearctic and Neotropical regions
}

\author{
Leliane Silva Commar ${ }^{1}$, Luis Gustavo da Conceição Galego ${ }^{2}$, Carlos Roberto Ceron ${ }^{3}$ \\ and Claudia Marcia Aparecida Carareto ${ }^{1}$ \\ ${ }^{1}$ Departamento de Biologia, Universidade Estadual Paulista "Júlio de Mesquita Filho", \\ São José do Rio Preto, SP, Brazil. \\ ${ }^{2}$ Departamento de Ciências Biológicas, Instituto de Ciências Exatas e Naturais, \\ Universidade Federal do Triângulo Mineiro, Uberlândia, MG, Brazil. \\ ${ }^{3}$ Departamento de Química e Ciências Ambientais, Universidade Estadual Paulista \\ "Júlio de Mesquita Filho”, São José do Rio Preto, SP, Brazil.
}

\begin{abstract}
Zaprionus indianus is a dipteran (Drosophilidae) with a wide distribution throughout the tropics and temperate Palearctic and Nearctic regions. There have been proposals to reclassify the genus Zaprionus as a subgenus or group of the genus Drosophila because various molecular markers have indicated a close relationship between Zaprionus species and the immigrans-Hirtodrosophila radiation within Drosophila. These markers, together with alloenzymes and quantitative traits, have been used to describe the probable scenario for the expansion of Zaprionus indianus from its center of dispersal (Africa) to regions of Asia (ancient dispersal) and the Americas (recent dispersal). The introduction of $Z$. indianus into Brazil was first reported in 1999 and the current consensus is that the introduced flies came from high-latitude African populations through the importation of fruit. Once in Brazil, $Z$. indianus spread rapidly throughout the Southeast and then to the rest of the country, in association with highway-based fruit commerce. These and other aspects of the evolutionary biology of $Z$. indianus are addressed in this review, including a description of a probable route for this species' dispersal during its recent expansion.
\end{abstract}

Key words: alloenzyme, bioinvasion, molecular markers, phylogenetic analysis, quantitative traits.

Received: September 15, 2011; Accepted: February 28, 2012.

\section{Introduction}

A little more than 10 years ago, Zaprionus indianus (Gupta, 1970), a drosophilid belonging to the genus Zaprionus and the subgenus of the same name, was introduced into Brazil and became a major pest affecting fig production (Vilela, 1999) giving rise to its Brazilian common name of fig fly. Vilela et al. (2001) and Stein et al. (2003) provided detailed descriptions of the species immediately after its introduction. Briefly, Z. indianus is approximately $3 \mathrm{~mm}$ long, has red eyes and a brown body with longitudinal white bands interspersed with black bands on the back of the head and thorax. In addition to being a human commensal, $Z$. indianus is a generalist species that uses a variety of endemic and introduced fruits as sites for mating and oviposition (Lachaise and Tsacas, 1983; Schmitz et al., 2007). Zaprionus indianus feeds on the bacteria and yeast found in decomposing fruits, principally on the yeast Candida tropicalis (Gomes et al., 2003). Based on the vari-

Send correspondence to Claudia M.A. Carareto. Departamento de Biologia, Universidade Estadual Paulista (UNESP), São José Rio Preto, 15054-000, SP, Brazil. E-mail: carareto@ ibilce.unesp.br. ous locations where this organism has been found, it is believed that $Z$. indianus lives on 80 host plants, making this species the most ecologically diverse drosophilid in the Afrotropical fauna (Yassin and David, 2010). This generalist characteristic is perhaps one of the principal factors contributing to the success of $Z$. indianus in tropical and subtropical regions.

There has been much speculation about the phylogenetic position of $Z$. indianus within the genus and subgenus Zaprionus (Drosophilidae). This species has aroused great interest in the Brazilian scientific community because of its recent introduction and rapid dispersal, first throughout Brazil and then across a large part of the South American continent. These and other aspects of the evolutionary biology of $Z$. indianus are addressed in this review, which includes an attempt to trace a probable route of dispersal for this species during its recent expansion.

\section{Phylogenetic relationships of the genus Zaprionus}

The genus Zaprionus is divided into two subgenera that are distinguished by their geographic origin: the subge- 
nus Anaprionus (Okada, 1990) contains 10 species from the Oriental biogeographic region (Okada and Carson, 1983; Wynn and Toda, 1988; Gupta and Gupta, 1991) and the subgenus Zaprionus comprises 49 essentially Afrotropical species (Okada and Carson, 1983; Yassin et al., 2008a,b). Chassagnard and Tsacas (1993) classified the species of the subgenus Zaprionus into two groups, inermis and armatus, with the latter comprising three subgroups: armatus, tuberculatus and vittiger. Recent phylogenetic revisions using molecular and morphological characters have shown Zaprionus s.s. species to be monophyletic, but both species groups to be polyphyletic (Yassin et al., 2008a). Based on these recent phylogenetic findings, a new classification of the subgenus Zaprionus has been proposed and includes a redefinition of the boundaries of the armatus and inermis species groups. The vittiger subgroup was upgraded to the level of a species group and the tuberculatus subgroup was transferred from the armatus to the inermis group (Yassin and David, 2010). Zaprionus indianus was included in the armatus group and vittiger subgroup (now group) by Chassagnard (1996), as mentioned above. Gupta (1970) proposed the epithet indianus for the species, probably because the type specimen used for identification came from India; he was probably unaware of the distribution of the species throughout the entire Afrotropical region (Vilela et al., 2001). This was not, however, the only misunderstanding related to the identification of this species. Tsacas (1985) reviewed all of the problems concerning the nomenclature of $Z$. indianus and pointed out that synonymous species names include Z. inermis (Séguy, 1983), Z. paravittiger (Goodbole and Vaidya, 1972) and Z. collarti (Tsacas, 1980). He also noted that $Z$. vittiger (Coquillet, 1901) can easily be misidentified as $Z$. indianus.

The genus Zaprionus has also been the subject of much discussion regarding its proper phylogenetic position within the Drosophilidae. The first attempt to establish phylogenetic relationships within this family was by Throckmorton (1962, 1975). Using biogeographic, anatomical and behavioral data, Throckmorton (1975) characterized the Drosophilidae as a paraphyletic group and considered Zaprionus to be a subgenus of Drosophila within the immigrans-Hirtodrosophila radiation. Throckmorton's classification was criticized because he did not use the concept of monophyly. Other researchers proposed new phylogenetic relationships among drosophilids. For example, Grimaldi (1990) used cladistic analysis to construct a phylogenetic tree for Drosophila and related genera based on 217 morphological characteristics of 120 representative species. In this phylogeny, the subgenera Hirtodrosophila, Scaptomyza, Idyomia and Zaprionus were excluded from the genus Drosophila. Despite the fact that mitochondrial DNA analyses by De Salle (1992) corroborated Grimaldi's proposal, the majority of phylogenies that were constructed thereafter based on molecular markers conflicted with these authors proposals and frequently placed species of Zaprionus within the genus Drosophila.

Three of the early molecular phylogenies included species from Zaprionus on a branch between the subgenera Drosophila and Sophophora of the genus Drosophila. These phylogenies were constructed using the gene sequences of the alcohol dehydrogenase enzyme (Adh) (Thomas and Hunt, 1993), copper/zinc superoxide dismutase (Kwiatowski et al., 1994) or the two concatenated gene sequences (Cu/Zn Sod and Adh; Russo et al., 1995). The great majority of phylogenetic analyses, however, link species of the genus Zaprionus to the subgenus Drosophila. Based on ribosomal RNA sequences from 72 species of Drosophilidae, Pelandakis and Solignac (1993) placed the species of Zaprionus (Z. inermis, Z. sepsoides, Z. capensis, $Z$. taronus and $Z$. lineosus) in a single clade within the subgenus Drosophila, in close proximity to the immigrans and repleta groups. Kwiatowski and Ayala (1999) subsequently used sequences of the genes $A d h$, Sod and Gpdh to place Zaprionus in the same clade as D. immigrans. Other analyses produced similar results, placing Zaprionus close to $D$. immigrans but not within the same clade. This is the case for the study by Powell and De Salle (1995), who analyzed mitochondrial and ribosomal sequences as well as morphological and behavioral data. It is also true for the study by Remsen and De Salle (1998) who, in addition to the data used by Powell and De Salle (1995), analyzed nucleotide sequences of the genes Adh and Sod. In contrast, the phylogenetic analysis by Tatarenkov et al. (1999), which used four nuclear markers ( $D d c$, Sod, Adh and Gpdh), placed Zaprionus (as well as Scaptomyza) in a position that formed a sister clade with the virilis and repleta groups. In this study, Tatarenkov et al. (1999) proposed for the first time that the taxon Zaprionus should be considered a subgenus of the genus Drosophila.

More recent studies, such as those of Robe et al. (2005), which analyzed the nuclear genes alpha methyl dopa $(a m d)$ and mitochondrial cytochrome oxidase II (COII), and Da Lage et al. (2007), which used sequences of the gene Amyrel, placed Zaprionus within the immigransHirtodrosophila radiation of the subgenus Drosophila, thus corroborating Throckmorton's original proposal of 1975. At the same time, a study using the Amyrel gene, the COII gene and morphological characteristics has linked Zaprionus to the tumiditarsus group, which is basically classified as part of the subgenus Drosophila (Yassin, 2007).

Doubts about the phylogenetic relationships of drosophilids are not restricted to the genus Zaprionus. A phylogenetic reconstruction by van der Linde and Houle (2008) combined 117 trees to produce a "supertree" that corroborated the paraphyly of the genus Drosophila and placed Zaprionus among species of the immigranstripunctata radiation, which is currently the most accepted position. These results support a new classification for the 
genus Zaprionus in which it is a subgenus of the genus Drosophila or even a group within the subgenus Drosophila. However, to understand the evolutionary relationships of the genus Zaprionus better it is necessary to perform complementary analyses that use a larger number of molecular markers and morphological characteristics. Nevertheless, most studies indicate that the diversification of Zaprionus occurred after the origin of the subgenus Sophophora, making Zaprionus more related to the subgenus Drosophila than to Sophophora. However, the exact phylogenetic relationship between Zaprionus (and other drosophilids) and the genus Drosophila is still a matter for speculation.

\section{Evolution and geographic distribution of the genus Zaprionus}

The genus Zaprionus is currently believed to have arisen in the Oriental region (Okada, 1981) relatively recently, during the Late Miocene ( $\sim 10$ million years ago), as compared to the origin of the subgenus Drosophila $(\sim 60$ MYA) (Yassin et al., 2008a). Using mitochondrial (COII) and nuclear (Amyrel) markers and a reconstruction of historical biogeography, Yassin et al. (2008a) proposed that immediately after its origin in the East, during the Quaternary ( $\sim 7$ MYA), an ancestral lineage of the subgenus Zaprionus colonized Africa via a maritime route from the islands of the Indian Ocean. Thereafter, most of the morphological and ecological diversification of the subgenus took place in West Africa during the cyclic climatic changes of the Quaternary. In this analysis, the authors adopted the Chassagnard and Tsacas (1993) classification of the subgenus Zaprionus. However, as commented above, the groups and subgroups have been redefined in the light of a more recent phylogenetic analysis (Yassin and David, 2010). In order to provide an overview of the diversification of the subgenus in tropical Africa, in this discussion we have followed strictly the description by Yassin et al. (2008a), although it is important to note that the tuberculatus subgroup was transferred from the armatus to the inermis group and the vittiger subgroup (from the armatus group) was upgraded to species level. In short, the two groups of the subgenus Zaprionus evolved in tropical Africa: the inermis group, which evolved first in the islands of the Indian Ocean ( $6.9 \pm 0.8 \mathrm{MYA})$ but with many independent dispersal events between the African continent and these islands, especially during the Pleistocene, and the armatus group, which appeared later $(4.4 \pm 0.9$ MYA) in Central Africa, during the Early Pliocene. This diversification of the subgenus Zaprionus in Africa and the islands of the Indian Ocean occurred in parallel with the evolution of the species of the subgroup melanogaster of the group melanogaster in the genus Drosophila (Lachaise et al., 1988; Lachaise and Silvain, 2004). Recently, three distantly related Afrotropical species ( $Z$. indianus, $Z$. tuberculatus and $Z$. ghesquierei) became invasive and have been found in the Palearctic region (Chassagnard and Kraaijeveld, 1991). Zaprionus indianus is the most widespread species of the genus and occurs over a broad range on four continents (Asia, Africa and the Americas).

\section{Ecological, ethological and evolutionary features shared between Zaprionus and Drosophila and genomic invasion by transposable elements}

The similarities between species of the genus Zaprionus and species of the subgroup melanogaster in terms of their evolutionary characteristics and their ecological diversity have been highlighted in evolutionary studies (de Setta et al., 2009, 2011). As mentioned above, the origin of the subgenus Zaprionus dates back to the Late Miocene ( 7 MYA) in tropical Africa (Yassin et al., 2008a), and the species included in this subgroup originated between 4.3 and 6.9 MYA. Interestingly, the subgroup melanogaster arose at the same time and in the same geographic region. The subgroup melanogaster diversified in tropical Africa from a proto-melanogaster lineage that migrated from the East about 17-20 MYA. In West Africa, the complexes erecta and yakuba evolved approximately 1315 and 8-15 MYA, respectively, and the complex melanogaster, the origin of the lineages that gave rise to $D$. melanogaster on one side and to the subcomplex simulans on the other, emerged about 2-3 MYA. This subcomplex produced $D$. simulans, D. sechellia and D. mauritiana, apparently from the same diversification event, only about 400,000 years ago (Lachaise et al., 1988; Lachaise and Silvain, 2004). This superposition of time and place of origin and diversification allows for evolutionary studies involving the comparison of genetic, morphological and behavioral data. Some of the studies done have involved the analysis of sequences of transposable elements (e.g., mariner, Hosimary, gypsy, copia and micropia) in species of the two groups (Maruyama and Hartl, 1991; Lawrence and Hart1, 1992; Brunet et al., 1994, 1999; Jordan and McDonald, 1998; Heredia et al., 2004; de Almeida and Carareto, 2006; Ludwig and Loreto, 2007; Ludwig et al., 2008; Vidal et al., 2009; de Setta et al., 2009, 2011; Deprá et al., 2010). These studies found similarities between the sequences of transposable elements from the subgenus Zaprionus and from certain species of the subgroup melanogaster that were greater than the similarities between species of the same species group. In addition, these elements do not occur in other species of the group melanogaster. The studies cited above indicate that these elements were involved in instances of horizontal transfer between the species of the two genera.

The sharing of transposable elements via horizontal transfer requires spatial, temporal and ecological overlap. Drosophilids are saprophagic species that develop in decomposing plant material, including fruits, leaves and flowers, as well as fungi. Species of the group melanogaster tend to use decomposing fruits, flowers and 
other plant parts as substrates for feeding and mating; species of the genus Zaprionus also mate on flowers and fruits (Markow and O'Grady, 2006, 2008) and feed on this material and on microorganisms involved in decomposition. These microorganisms are eliminated in the feces and deposited at mating sites and on the surfaces of eggs (Bakula, 1969; Gilbert, 1980). This environment is thus rich in potential vectors for the horizontal transfer of transposable elements such as symbiotic bacteria (Hotopp et al., 2007), viruses (Fraser et al., 1996) and parasites such as ticks (Gilbert, 2010), mites (Houck et al., 1991) and wasps (Yoshiyama et al., 2001).

In addition to their shared ecological characteristics, the historic and contemporary geographic coexistence between species of the subgroup melanogaster and the subgenus Zaprionus suggests that these two groups of species passed through a period that allowed the transfer of transposable elements during their diversification. The invasive potential of various species of both groups, such as $D$. melanogaster (David and Capy, 1988), D. simulans (Hamblin and Veuille, 1999), D. malerkotliana (Vogl et al., 2003), D. ananassae (Val and Sene, 1980) and Zaprionus indianus (Gupta, 1970) may have promoted horizontal transfer events (for a detailed review, see Carareto, 2011).

\section{Intercontinental colonization by Zaprionus indianus}

Zaprionus indianus probably originated in Africa (Tsacas et al., 1981, 1985; David et al., 2006a,b; Yassin et al., 2008a,b) and can be considered one of the most successful colonizing species of its genus. The rapid geographic expansion of this species has led to many hypotheses on the processes involved in this invasion. Yassin et al. (2008b) studied the distribution of mitochondrial haplotypes of the COI and COII genes in 23 geographically distinct populations of $Z$. indianus and detected two phylogenetic lineages. Lineage 1 included three African populations, which supported the African origin of this species. A distinct phylogenetic pattern was observed in lineage II. The Atlantic populations (of the Americas and the island of Madeira) were closer to the ancestral African populations than to those of the East (Madagascar, Middle East and India), indicating that $Z$. indianus underwent two independent radiations: an older radiation in which it spread from East Africa to the East, and a more recent radiation in which it spread to the West (via the Atlantic). The various hypotheses explaining the two great invasions (Old World, Asia; New World, Americas) are described below.

\section{The colonization of Asia}

The colonization of Asia may have occurred only 30 years ago (David et al., 2006a), based on the description by Gupta (1970) using type specimens from India, or it may have occurred centuries ago (Karan et al., 2000). This process is not well documented and some authors even claim that $Z$. indianus is endemic to India (Gupta, 1970) and Paki- stan (Shakoori and Butt, 1979). However, Z. indianus has not been recorded in nearby Sri Lanka (Karan et al., 2000). Zaprionus indianus has been found in the Comoro Islands, the Canary Islands and Madagascar (Chassagnard and Tsacas, 1993), as well as in Saudi Arabia (Amoudi et al., 1991; 1993a,b) and in other parts of the Palearctic region (Chassagnard and Kraaijeveld, 1991).

The few records of $Z$. indianus in Asia include studies of quantitative traits and alloenzyme polymorphisms. In Indian populations, the sizes of the body, thorax and wings are reduced at higher temperatures (Karan et al., 1999), and various quantitative (weight, body and wing size) and reproductive (number of ovarioles) traits increase with latitude. The quantitative traits (wing, thorax and body size) also increase with altitude (Karan et al., 2000). The geographical characteristics (latitude and longitude) are not selective factors themselves, but they may be related to some form of climatic selection (Karan et al., 2000). Thus, these data provide indirect evidence of the action of natural selection, probably driven by variation in temperature. Various authors have suggested that increased body size may improve flying ability (Stalker, 1980; David et al., 1994; Azevedo et al., 1998).

Clines related to alloenzyme polymorphisms are generally attributed to greater or lesser stability of the variants, depending on the temperature (Hedrick, 1983; Parkash and Sharma, 1993; Parkash and Yadav, 1993a). Thermoresistant variants would be at advantage in environments with a higher ambient temperature (low latitudes and altitudes), and thermosusceptible variants would be at advantage in environments with lower temperatures (higher latitudes and altitudes). Environments with significant temperature variation during the year could support populations with variants of both types or with greater than expected heterozygosity resulting from balanced selection (Parkash and Sharma, 1993; Parkash and Yadav, 1993a).

Studies of different alloenzyme markers in Indian populations of $Z$. indianus have found that the markers show latitudinal clinal variation, including, for example, polymorphisms of the alloenzymes ACPH, esterases and MDH (Parkash and Sharma,1993), Acph-1 ${ }^{\mathrm{S}}$, Acph-1 ${ }^{\mathrm{F}}$, Mdh- $1^{\mathrm{F}}, \mathrm{Ao}^{\mathrm{S}}, \mathrm{Adh}^{\mathrm{F}}$, Est-1 and 2 and $\alpha-\mathrm{Gpdh}^{\mathrm{F}}$ (Parkash and Yadav, 1993b;Yadav and Parkash, 1993a; Parkash et al., 1994) and the allele $\operatorname{Adh}^{\mathrm{F}}$ (Yadav and Parkash, 1993b). Additionally, Parkash et al. (1992) found a significant increase in the frequency of the $\mathrm{Adh}^{\mathrm{F}}$ allele with increasing latitude while Yadav and Parkash (1993b) found that this variant increases tolerance to higher ethanol concentrations.

The clinal variation found in some Asian populations of $Z$. indianus is indicative of older colonization. The details of this colonization have been completely lost. However, the association of this drosophilid with altered environments and evidence that the recent colonization of the Americas probably occurred through the intercontinental transport of fruits (David et al., 2006b; Yassin et al., 
2009a; Galego and Carareto, 2010a), it is likely that the colonization of Asia occurred in a similar way during the great navigations at the end of the Middle Ages or beginning of the Modern period ( $15^{\text {th }}$ century) that involved the trading of spices and other products between the East and West. There are still questions, however, regarding the dispersal of $Z$. indianus in the Palearctic regions through the international fruit trade. For example, while in the Americas the dispersion of this species was extremely rapid (in approximately six years from São Paulo to Florida), it took more than 40 years for the species to spread from India to Egypt. The population in Egypt seems to be very recent in origin, more recent than December 2002 (Yassin et al., 2009a). This population may have come from a natural expansion from tropical Africa, through the Nile valley, or perhaps through trade in fruits from East Africa or Asia. Analyses of the polymorphisms of chromosomal inversions have shown that the populations in Alexandria (Egypt) are more closely related to Indian populations (Gupta and Kumar, 1987) than to African or Brazilian ones (Ananina et al., 2007). In addition, quantitative analyses of alloenzymes and RAPD have revealed low genetic variability in the Egyptian populations, a characteristic of recently introduced populations (Yassin et al., 2009b).

\section{The colonization of the Americas}

Vilela (1999) was the first to report the presence of $Z$. indianus in South America; the species was found in persimmons (Diospyros kaki, Ebenaceae) from Santa Isabel in São Paulo city in the state of São Paulo, Brazil. At the same time, the species was also collected at other locations in this state (Ribeirão Preto, São José do Rio Preto, and Valinhos) and in the Federal District (Vilela et al., 2001). Two hypotheses for the introduction of this species into Brazil were initially proposed by these authors. The less likely hypothesis was that some specimens had escaped from the drosophilid stocks at the Drosophila Species Resource Center in Austin, Texas, USA. The second hypothesis was that the introduction occurred directly through the air transport of contaminated foods from Africa to São Paulo.

A third hypothesis, proposed by Galego and Carareto (2007) as part of an analysis of esterase polymorphism, was that the introduction occurred through maritime transport in the Port of Santos (this port is a likely site, considering its commercial importance for Brazil: one quarter of all the products imported by Brazil passes through this port). According to the Food and Agriculture Organization (FAO, 1997) the global fruit market increased by $13 \%$ in the period 1985-1995. The volume of fruit transported and the special requirements for preservation mean that most of the fruit trade involves transport by sea (França and Gondin, 1999). According to data from the Brazilian Institute of Fruits (IBRAF, 2000-2001), Brazil imports mainly apples, cherries, grapes, kiwi, nectarines, peaches, pears and plums. Brazilian imports showed a significant increase from the 1970s to the 1990s, including imports from the African continent. Brazil currently has bilateral trade agreements with most countries in Africa (Ministério de Relações Exteriores, 2007), especially South Africa, from where it imports ores and agricultural products, including grapes (Ministério do Desenvolvimento, 2007). The importance of the fruit trade for the dissemination of this species in Brazil was initially suggested by Tidon et al. (2003). Galego and Carareto (2007) suggested that after its introduction, Z. indianus spread throughout the state of São Paulo principally via the highway-based fruit trade.

The second and third hypotheses are the most likely because data from morphological, ecological and genetic markers indicate that the founding population was quite large (David et al., 2006a; Ananina et al., 2007; Galego and Carareto, 2007). However, regardless of how it was introduced, Z. indianus rapidly expanded its range; in little more than two years after its introduction, this drosophilid was present in practically all of the Brazilian states. As early as 1999, after the first report, the species was detected in Santa Catarina (Toni et al., 2001) and other areas of the Brazilian cerrado and Midwest (Tidon et al., 2003). In 2000, the species reached Rio Grande do Sul (Castro and Valente, 2001), Rio de Janeiro (Loh and Bitner-Mathé, 2005) and Uruguay (Goñi et al., 2001, 2002). In 2001, the species was recorded in different locations in Minas Gerais (Kato et al., 2004; David et al., 2006a), and in 2002 it was found in various states in the Northeast (Mattos-Machado et al., 2005). The species reached the state of Tocantins and the north of Brazil in 2003 (Santos et al., 2003) and was also recorded in Panama in 2003 (Central America). In 2005, Z. indianus was recorded in Florida (USA) (van der Linde et al., 2006) and Argentina (Soto et al., 2006). This rapid and broad geographic dispersion is indicative of the great ease with which $Z$. indianus can colonize new environments. Figure 1 shows the worldwide distribution of $Z$. indianus (with Brazil highlighted) and the probable dates of colonization.

Interest in the study of $Z$. indianus is directly related to its recent invasion of Neotropical regions. Today, this species is considered to be semi-cosmopolitan (Vilela, 1999; Tidon et al., 2003; Silva et al., 2005a,b). This rapid expansion, in addition to the scarcity of information on $Z$. indianus until the last ten years, has motivated dozens of researchers to investigate the invasion by this species. Many of the studies that have investigated this invasion have used markers such as quantitative characteristics, alloenzyme polymorphisms, mitochondrial DNA, ecological analysis and even complete genome sequencing.

Variation in quantitative traits can be a good indicator of the amount of genetic variability in a species and can reveal the potential phenotypic plasticity of the species and its ability to exploit niches. Loh and Bitner-Mathé (2005) detected significant variation in wing size and form in populations of $Z$. indianus in Rio de Janeiro. David et al. (2006a) analyzed three quantitative characteristics (wing 


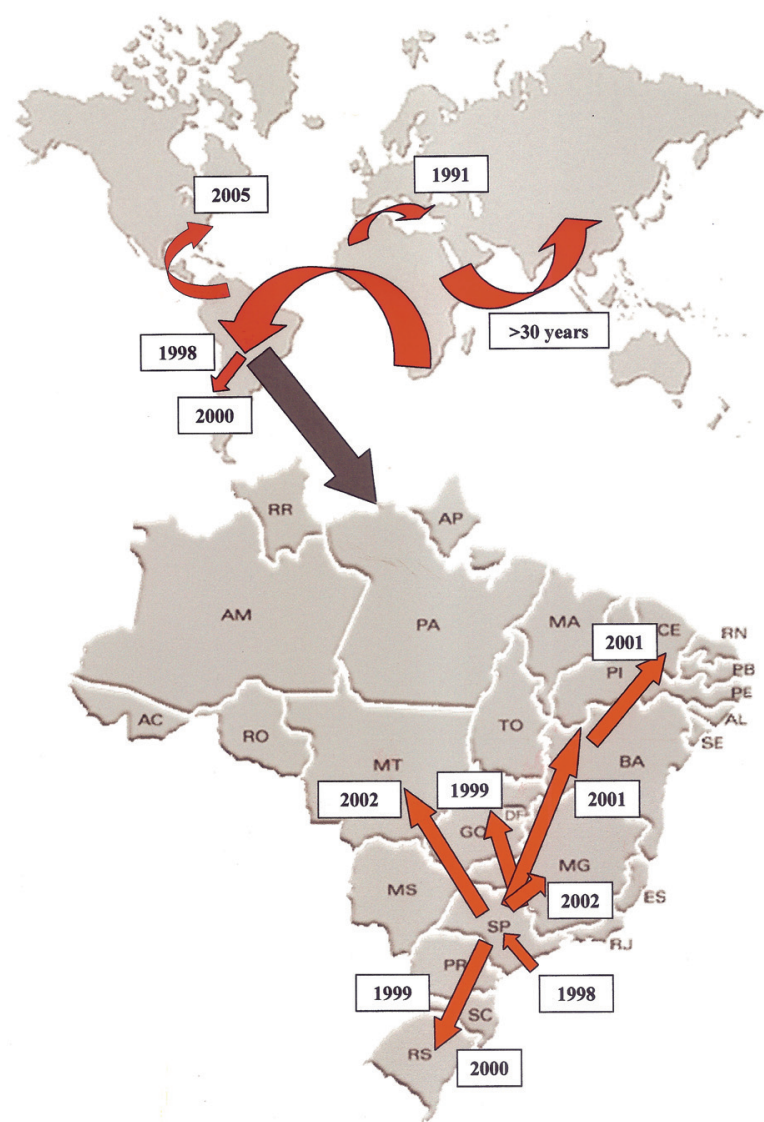

Figure 1 - Migration routes for $Z$. indianus involved in its dispersal throughout the world, based on studies cited in the text. The process that occurred in Brazil is highlighted.

size, thorax size and number of sternopleural bristles) in African, Indian and Brazilian populations of $Z$. indianus and found clinal variation in the Indian populations that was less marked in the African populations and not detected in the Brazilian populations; however, the Brazilian populations showed significant interlineage differences. Based on these data, the authors suggested that the propagules that colonized Brazil were quite numerous and contained sufficient genetic variability to prevent a possible "bottleneck" effect. The authors also suggested that the colonization was quite recent, which would explain the lack of clinal variation in the quantitative traits. Analysis of the average body size of Brazilian $Z$. indianus suggested that South Africa was the probable origin of the founder propagules (David et al., 2006a). This conclusion regarding the African origin of the Brazilian populations was supported by the lack of significant differences between populations from these two geographic regions (David et al., 2006a). Chromosomal inversions also support the hypothesis of an African origin for the founder propagules of $Z$. indianus (Ananina et al., 2007). Only inversion In(II)A, one of the most frequent in Indian populations (Gupta and Kumar, 1987), was detected in Brazilian populations, but at a very low frequency. Ananina et al. (2007) also showed that Brazilian populations contained five other inversions not detected in Indian populations. The high rate of inversion polymorphisms, along with the fact that they are rarely shared with Indian populations, indicates that the founder propagules were quite numerous and that they did not stem from the latter populations.

In various drosophilids, the colonization of a new environment leads to an increase in genome size through enhanced transposition of transposable elements (Biemont and Vieira, 2005). The size of the $Z$. indianus genome as estimated by flow cytometry ranges from $0.601 \mathrm{pg}$ in Indian populations to $0.630 \mathrm{pg}$ in African populations and $0.635 \mathrm{pg}$ in Brazilian populations (Nardon et al., 2005). According to these authors the smaller genome size of Indian populations suggests a possible Asiatic origin for this drosophilid. Among the different markers studied to date, genome size is the only one that suggests a non-African origin for Z. indianus; however, the smaller genome size of the Indian populations may be the results of a recent bottleneck during occupation of the Palearctic region (Yassin et al., 2008b). At any rate, these data indicate that the Brazilian and African populations have a similar genome size, which again supports the idea that the founding Brazilian populations were of African origin.

Molecular markers have contributed considerably to understanding the introduction of Z. indianus into the Americas. Esterase alloenzymes were the first markers to be used. Galego et al. (2006) described six loci coding for esterases in $Z$. indianus, four of which encode $\alpha$-esterases and two encode $\beta$-esterases. Two of these loci, Est-3 (four alleles) and Est-2 (two alleles), were polymorphic. This polymorphism supports the hypothesis that South America was colonized by a large number of propagules. Mattos-Machado et al. (2005) also analyzed polymorphisms at five alloenzyme loci (Acp, Pgm, Idh, Hk and Est-3) in Brazilian, Asiatic and African populations of $Z$. indianus and detected a low $F_{\text {ST }}$ among the Brazilian populations, which suggested colonization by a single propagule with subsequent rapid expansion. Although these authors did not suggest the origin of the propagule, they stated that it probably included almost all of the polymorphisms that existed in the ancestral population. An African origin for $Z$. indianus is also supported by the analysis of neutral polymorphisms, which are more appropriate for phylogeographic studies than alloenzymes, such as the mitochondrial genes COI and COII (Yassin et al., 2008b; Commar, Ceron, Carareto, unpublished data). Additionally, it has been also reinforced by analysis of the nuclear gene $\beta$ esterase- 6 (Commar, Ceron, Carareto, unpublished data).

\section{Biological characteristics of Zaprionus indianus related to colonization in the Neotropical region}

Zaprionus indianus is a generalist species that uses a variety of domestic and non-domestic fruits as sites for mating and oviposition (Lachaise and Tsacas 1983; 
Schmitz et al., 2007). In Brazil, Z. indianus has adopted a behavior never seen before among drosophilids, namely, the colonization of unripe fruits, making them inedible to humans and causing extensive economic damage (Castro and Valente, 2001). Although not considered a pest in its place of origin, the invasion of Brazil by this drosophilid has resulted in considerable agricultural losses. In 1999, Z. indianus was responsible for the loss of $40 \%$ of the fig harvest (Ficus carica) in the main productive region in the state of São Paulo (Stein et al. 2000). As a result, Z. indianus was classified as a pest at the time; however, this behavior must have been a single, one-off event that characterized the introduction of $Z$. indianus into Brazil (van der Linde et al., 2006).

Some characteristics of $Z$. indianus, such as its variation in body size, are similar to those of populations found on other continents (Yassin et al., 2009b). Body size may be related to the success of invading species (Cassey, 2000; Roy et al., 2002; Fisher and Owens, 2004). The variability in fly size in a population of $Z$. indianus in the Nile delta, which has a Mediterranean climate, was initially attributed to the highly heterogeneous environment of this region, including high temperatures, stress, dehydration and exposure to insecticides (Yassin et al., 2007). Yassin et al. (2009b) examined this hypothesis by investigating other populations of the same species living in a completely different and more benign tropical environment, such as close to the tropics in Brazil, where the climate is wet and humid. The populations sampled were genetically different from the Egyptian population, as shown by cytogenetic (Ananina et al., 2007) and molecular (Yassin et al., 2008b) studies. The authors showed that contrary to expectation, body size variability was always very high and similar across populations and continents. These results suggested that the elevated phenotypic variability in $Z$. indianus may be an intrinsic property of this species and may be related to the ability to use a wide diversity of resources and microhabitats.

Other studies that have examined the invasive potential of $Z$. indianus have focused on the life cycle (Amoudi et al., 1991), larval competition (Amoudi et al., 1993a) and fitness components (Amoudi et al., 1993b) in lineages originating in Saudi Arabia. Zaprionus indianus is a tropical species that is easily reared at $31^{\circ} \mathrm{C}$ (Amoudi et al., 1991; Karan et al., 1999; Araripe et al., 2004; Loh et al., 2008) but is sensitive to cold. The optimal temperature for successful development of flies from Saudi Arabia is $20-30{ }^{\circ} \mathrm{C}$, with no development at $35^{\circ} \mathrm{C}$ (Amoudi et al., 1991, 1993b). This sensitivity to variation in temperature is an important factor in the establishment of this species in varied environments such as Saudi Arabia, where elevated temperatures are frequent during the summer.

Alloenzyme studies indicate that the distribution of genetic variability at the $\alpha$-esterase 3 locus in $Z$. indianus is influenced by natural selection, including selection by in- secticides and selection stemming from climatic variation (Galego and Carareto, 2007, 2010b). Plasticity in the distribution of allele frequencies for the Est-3 locus may also have contributed to the successful spread of this organism, especially in the American continent, given that esterases perform multiple essential functions in insects.

Until the end of the 1990s, few studies had examined the life cycle of $Z$. indianus. Stein et al. (2003) and Setta and Carareto (2005) contributed significantly to our understanding of the life cycle of $Z$. indianus populations. These studies reported a greater longevity than in Z. indianus populations of Indian (Bains et al., 1995, 1996) and Saudi Arabian (Amoudi et al., 1991, 1993a) origin. The productivity of the species was similar to or greater than that of other drosophilids and the development time was very similar to that of $D$. sturtevanti. These results indicated an $r$-strategy of environment colonization, which is highly characteristic of bioinvaders.

Fitness components, such as development time, productivity and fertile period are strongly linked to the reproductive biology of a species, with fecundity and productivity being directly related to the production of ova and sperm. Araripe et al. (2004) demonstrated that the viability of male gametes in $Z$. indianus was temperature-dependent, such that very low ambient temperatures led to male sterility. If development occurred at $15^{\circ} \mathrm{C}$, all of the males were sterile. This drastic reduction in reproductive capacity could explain why $Z$. indianus is not found in higher latitude regions, as already reported by Chassagnard and Kraaijeveld (1991) and Goñi et al. (2001, 2002).

We do not know how the species survives periods of cold, i.e., if there is diapause or if populations are able to recover through reintroduction. One hypothesis suggested by Danni (1980) involves the formation of islands of heat in cold regions, as for example in the southern Brazilian city of Porto Alegre. This phenomenon is associated with urbanization. These thermal islands could be used as refuges by urban insect populations during unfavorable periods. Oscillations in the frequencies of different species reflect variations in their tolerance to variable climatic conditions at a single location. According to Tidon (2006), some drosophilid species are extremely seasonal and only appear at particular times of the year. In agreement with this, the highest frequencies of $Z$. indianus were recorded during the seasons with the highest average temperatures (spring and summer), whereas sightings were lowest during the fall and winter but increased again in the spring. Such fluctuations reinforce the invasive capacity of this species (Tidon et al., 2003). Similar behavior was observedby Silva et al. (2005a) in three urban parks of Porto Alegre over seven seasons. In this case, $Z$. indianus showed the highest frequencies compared to other drosophilids during the seasons with the highest mean temperatures, but the frequency consistently dropped during autumn and winter to increase again in the spring. The authors concluded that the ability to 
live in environments associated with humans and the capacity to restore high population levels under favorable conditions contributed to this species expansion and colonization of new areas.

The distribution of $Z$. indianus across different continents and its establishment in these areas is related to the climatic conditions that it encounters. Mata et al. (2010) used multivariate analysis to show that $Z$. indianus occupies different niches in Africa, Asia and the Americas such that the climatic conditions of the area occupied by the original population differ from those of areas where it is new, principally in India. Indeed, populations of $Z$. indianus in India established themselves in climates very different from those of Africa, where the temperatures are more variable and considerably lower in the colder months. The clinal variation in several characteristics of the Indian populations of $Z$. indianus (Karan et al., 2000) may reflect the adaptation of these flies to these conditions. Changes in niche can occur through adaptive responses to new environmental conditions in the invaded areas and these changes may be driven by natural selection for climatic tolerance (Mata et al., 2010). In South America, invading $Z$. indianus encountered climatic conditions very similar to their original niche that allowed the rapid establishment and expansion of this species throughout Brazil.

Studies on the distribution of $Z$. indianus in Brazil have shown variation in the abundance of this species among ecosystems. Tidon et al. (2003) analyzed the abundance of $Z$. indianus in the cerrado and riverine forests and found a greater abundance in the cerrado during wet periods. Ferreira and Tidon (2005) showed that, together with D. simulans, $Z$. indianus was the most abundant species in the urbanized environment of Brasília, the Brazilian capital. On the other hand, the abundance of this fly in mangrove forests was higher than in the Atlantic rain forest but lower than in the cerrado (Tidon et al., 2003) or in urban environments (Ferreira and Tidon 2005; Silva et al., 2005b). These results indicate that together with other introduced Drosophilidae, $Z$. indianus could be useful as an indicator of disturbed areas.

In addition to the factors discussed above, the variation in $Z$. indianus abundance may also reflect competitive interactions with other drosophilids. An experimental study has shown a reduction in the viability of $Z$. indianus in the presence of larval waste from $D$. sturtevanti; on the other hand, waste from $Z$. indianus interferes with the viability of D. simulans and the duration of development in both of these Drosophila species (Galego and Carareto, 2007). Thus, competitive interactions between $Z$. indianus and other drosophilids may affect the population density of this species after its introduction into a new environment. Other factors, such as temperature tolerance and plasticity in the occupation of niches (involving the use of a wide variety of plants as food sources) may also be related to this species invasive success.

\section{Acknowledgments}

CMAC and LSC were supported by Conselho Nacional de Desenvolvimento Científico e Tecnológico (CNPq).

\section{References}

Almeida LM and Carareto CM (2006) Sequence heterogeneity and phylogenetic relationships between the copia retrotransposon in Drosophila species of the repleta and melanogaster groups. Genet Sel Evol 38:535-550.

Amoudi MA, Diab FM and Abou-Fannah SSM (1991) Zaprionus indianus Gupta (Diptera, Drosophilidae) in Saudi Arabia and the effect of temperature on the life cycle. J King Saud Univ Agri 3:25-35.

Amoudi MA, Diab FM and Abou-Fannah SSM (1993a) Effects of larval population density on the life cycle parameters in Zaprionus indianus Gupta (Diptera, Drosophilidae). Pakistan J Zool 25:37-40.

Amoudi MA, Diab FM and Abou-Fannah SSM (1993b) The influence of low temperature on development, adult longevity and productivity of Zaprionus indianus Gupta (Diptera, Drosophilidae). J King Saud Univ Agri 5:263-274.

Ananina G, Rohde C, David JR, Valente VL and Klaczko LB (2007) Inversion polymorphism and a new polytene chromosome map of Zaprionus indianus Gupta (1970) (Diptera, Drosophilidae). Genetica 131:117-125.

Araripe LO, Klaczko LB, Moreteau B and David JR (2004) Male sterility thresholds in a tropical cosmopolitan drosophilid, Zaprionus indianus. J Therm Biol 29:73-80.

Azevedo RBR, James AC, McCabe J and Partridge L (1998) Latitudinal variation of wing: Thorax size ratio and wing aspect ratio in Drosophila melanogaster. Evolution 52:1353-1362.

Bains JS, Kakkar R, Sharma SP and Garg SK (1995) Longevity is affected by vitamin feeding in banana fruit fly, Zaprionus paravittiger. Biosci Res Bull 5-7:13-16.

Bains JS, Kakkar R and Sharma SP (1996) Gender specific alterations in antioxidant status of aging Zaprionus paravittiger fed on propyl gallate. Biochem Mol Biol Int 40:731-740.

Bakula M (1969) Persistence of a microbial flora during postembryogenesis of Drosophila melanogaster. J Invertebr Pathol 14:365.

Biemont C and Vieira C (2005) What transposable elements tell us about genome organization and evolution: The case of Drosophila. Cytogenet Genome Res 110:25-34.

Brunet F, Godin F, David JR and Capy P (1994) The mariner transposable element in the Drosophilidae family. Heredity 73:377-385.

Brunet F, Godin F, Bazin C and Capy P (1999) Phylogenetic analysis of Mos1-like transposable elements in the Drosophilidae. J Mol Evol 6:760-768.

Carareto CMA (2011) Tropical Africa as a cradle for horizontal transfers of transposable elements between species of the genus Drosophila and Zaprionus. Mob Genet Elements 3:179-183.

Cassey P (2000) Life history and ecology influences establishment success of introduced land birds. Biol J Linn Soc 76:465-480.

Castro FL and Valente VLS (2001) Zaprionus indianus invading communities in the southern Brazilian city of Porto Alegre. Drosophila Inf Serv 84:15-17. 
Chassagnard MT (1996) Les espèces africaines du sous-genre Zaprionus S.STR. à six bandes thoraciques (Diptera, Drosophilidae). Ann Soc Entomol Fr 32:59-65.

Chassagnard MT and Kraaijeveld AR (1991) The occurrence of Zaprionus sensu stricto in the Palearctic region (Diptera, Drosophilidae). Ann Soc Entomol Fr 27:495-496.

Chassagnard MT and Tsacas L (1993) Le sous-genre Zaprionus s.str. Définition de groupes d'espèces et revision du sousgroupe vittiger (Diptera, Drosophilidae). Ann Soc Entomol Fr 29:173-194.

Da Lage JL, Kergoat GJ, Maczkowiak F, Silvain JF, Cariou ML and Lachaise D (2007) A phylogeny of Drosophilidae using the amyrel gene: Questioning the Drosophila melanogaster species group boundaries. J Zoolog Syst Evol Res 45:47-63.

Danni IM (1980) A ilha térmica de Porto Alegre: Contribuição ao estudo do clima urbano. Bol Gaúcho Geogr 8:33-47.

David JR and Capy P (1988) Genetic variation of Drosophila melanogaster natural populations. Trends Genet 4:106-111.

David JR, Moretau B, Gauthier JP, Pétavy G, Stockel J and Imasheva AG (1994) Reaction norms of size characters in relation to growth temperature in Drosophila melanogaster: An isofemale lines analyses. Genet Sel Evol 26:229-251.

David JR, Araripe LO, Bitner-Mathe BC, Capy P, Goñi B, Klaczko LB, Legout H, Martins MB, Vouidibio J, Yassin A, et al. (2006a) Sexual dimorphism of body size and sternopleural britle number: A comparison of geographic population of an invasive cosmopolitan drosophilid. Genetica 128:109-122.

David JR, Araripe LO, Bitner-Mathé BC, Capy P, Goñi B, Klaczko LB, Legout H, Martins MB, Vouidibio J, Yassin A, et al. (2006b) Quantitative trait analyses and geographic variability of natural populations of Zaprionus indianus, a recent invader in Brazil. Heredity 96:53-62.

De Salle R (1992) The origin and possible time of divergence of the Hawaiian Drosophilidae: Evidence from DNA sequences. Mol Biol Evol 9:905-916.

de Setta N, Van Sluys MA, Capy P and Carareto CM (2009) Multiple invasions of Gypsy and Micropia retroelements in genus Zaprionus and melanogaster subgroup of the genus Drosophila. BMC Evol Biol 9:e279.

de Setta N, Van Sluys MA, Capy P and Carareto CM (2011) Copia retrotransposon in the Zaprionus genus: Another case of transposable element sharing with the Drosophila melanogaster subgroup. J Mol Evol 72:326-328.

Deprá M, Panzera Y, Ludwig A, Valente VL and Loreto EL (2010) Hosimary: A new hAT transposon group involved in horizontal transfer. Mol Genet Genomics 283:451-459.

Ferreira LB and Tidon R (2005) Colonizing potential of Drosophilidae (Insecta, Diptera) in environments with different grades of urbanization. Biodivers Conserv 14:1809-1821.

Fisher DO and Owens IPF (2004) The comparative method in conservation biology. Trends Ecol Evol 19:391-398.

Fraser MJ, Coszczon T, Elick T and Bauser C (1996) Precise excision of TTAA-specific lepidopteran transposons piggyBac(IFP2) and tagalong (TFP3) from the baculovirus genome in cell lines from two species of Lepidoptera. Insect Mol Biol 5:141-151.

Galego LGC and Carareto CMA (2007) Analysis of the drosophilid Zaprionus indianus introduction in Brazil: Contribution of esterase loci polymorphisms. Drosophila Inf Serv 90:79-84.
Galego LGC and Carareto CM (2010a) Scenario for the spreading of the invasive species Zaprionus indianus Gupta 1970 (Diptera, Drosophilidae) throughout Brazil. Genet Mol Biol 33:767-773.

Galego LG and Carareto CMA (2010b) Variation at the Est3 locus and adaptability to organophosphorous compounds in Zaprionus indianus populations. Ent Exp App 13:97-105.

Galego LGC, Ceron CR and Carareto CMA (2006) Characterization of esterases in a Brazilian population of Zaprionus indianus (Diptera, Drosophilidae). Genetica 126:89-99.

Gilbert DG (1980) Dispersal of yeasts and bacteria by Drosophila in a temperate forest. Oecologia 46:135-137.

Gilbert C, Schaack S, Pace JK, Brindley PJ and Feschotte C (2010) A role for host-parasite interactions in the horizontal transfer of transposons across phyla. Nature 464:1347-1350.

Gomes LH, Echeverrigaray S, Conti JH, Lourenco M, Vinicius M and Duarte KMR (2003) Presence of the yeast Candida tropicalis in figs infected by the fruit fly Zaprionus indianus (Diptera, Drosophilidae). Rev Microbiol 34:5-7.

Goñi B, Fresia P, Calviño M, Ferreiro MJ, Valente VLS and Basso da Silva L (2001) First record of Zaprionus indianus Gupta, 1970 (Diptera, Drosophilidae) in southern localities of Uruguay, South America. Drosophila Inf Serv 84:61-65.

Goñi B, Martinez ME, Techera G and Fresia P (2002). Increased frequencies of Zaprionus indianus Gupta, 1970 (Diptera, Drosophilidae) in Uruguay. Drosophila Inf Serv 85:75-80.

Grimaldi DA (1990) A phylogenetic revised classification of genera in the Drosophilidae (Diptera). Bull Am Mus Nat Hist 197:123-128.

Gupta JP (1970) Description of a new species of Phorticella zaprionus (Drosophilidae) from India. Proc Natl Acad Sci USA 36:62-70.

Gupta JP and Kumar A (1987) Cytogenetics of Zaprionus indianus Gupta (Diptera, Drosophilidae): Nucleolar organizer regions, mitotic and polytene chromosomes and inversion polymorphism. Genetica 74:19-25.

Gupta KK and Gupta JP (1991) Four new and two unrecorded species of Drosophilidae from India (Insecta, Diptera). Proc Zool Soc Calcuta 44:110-126.

Hamblin MT and Veuille M (1999) Population structure among African and derived populations of Drosophila simulans: Evidence for ancient subdivision and recent admixture. Genetics 153:305-317.

Hedrick PW (1983) Genetics of Populations. Science Books International, Boston, $629 \mathrm{pp}$.

Heredia F, Loreto ELS and Valente VL (2004) Complex evolution of gypsy in drosophilid species. Mol Biol Evol 21:1831-1842.

Hotopp JCD, Clark ME, Oliveira D, Foster JM, Fischer P, Torres MC, Giebel J, Kumar N, Ishmael N and Wang S (2007) Widespread lateral gene transfer from intracellular bacteria to multicellular eukaryotes. Science 317:1753-1756.

Houck MA, Clark JB, Peterson KR and Kidwell MG (1991) Possible horizontal transfer of Drosophila genes by the mite Proctolaelaps regalis. Science 253:1125-1128.

Jordan IK and McDonald JF (1998) Evolution of the copia retrotransposon in the Drosophila melanogaster species subgroup. Mol Biol Evol 15:1160-1171.

Karan D, Moreteau B and David JR (1999) Growth temperature and reaction norms of morphometrical traits in a tropical drosophilid: Zaprionus indianus. Heredity 83:398-407. 
Karan D, Dubey S, Moreteau B, Parkash R and David JR (2000) Geographical clines for quantitative traits in natural populations of a tropical drosophilid: Zaprionus indianus. Genetica 108:91-100.

Kato CM, Foureaux LV, César RA and Torres MP (2004) Ocorrência de Zaprionus indianus Gupta, 1970 (Diptera, Drosophilidae) no estado de Minas Gerais. Ciênc Agrotec 28:454-455 (Abstract in English).

Kwiatowski J and Ayala FJ (1999) Phylogeny of Drosophila and related genera: Conflict between molecular and anatomical analyses. Mol Phylogenet Evol 13:319-328.

Kwiatowski J, Skarecky D, Bailey K and Ayala FJ (1994) Phylogeny of Drosophila and related genera inferred from the nucleotide sequence of the $\mathrm{Cu}, \mathrm{Zn}$ SOD gene. J Mol Evol 38:443-454.

Lachaise D and Silvain JF (2004) How two Afrotropical endemics made two cosmopolitan human commensals: The Drosophila melanogaster-D. simulans paleogeographic riddle. Genetica 120:17-39.

Lachaise D, Cariou ML, David JR, Lemeunier F, Tsacas L and Ashburner M (1988) Historical biogeography of the Drosophila melanogaster species subgroup. Evol Biol 22:159-225.

Loh R and Bitner-Mathé BC (2005) Variability of wing size and shape in three populations of a recent Brazilian invader Zaprionus indianus (Diptera, Drosophilidae) from different habitats. Genetica 125:271-281.

Loh R, David JR, Debat V and Bitner-Mathé BC (2008) Adaptation to different climates results in divergent phenotypic plasticity of wing size and shape in an invasive drosophilid. J Genet 87:209-217.

Ludwig A and Loreto ELS (2007) Evolutionary pattern of the gtwin retrotransposon in the Drosophila melanogaster subgroup. Genetica 130:161-168.

Ludwig A, Valente V and Loreto ELS (2008) Multiple invasions of Errantivirus in the genus Drosophila. Insect Mol Biol 17:113-124.

Markow TA and O'Grady P (2006) Drosophila: A Guide to Species Identification and Use. Academic Press, London, $259 \mathrm{pp}$.

Markow TA and O'Grady P (2008) Reproductive ecology of Drosophila. Funct Ecol 22:747-759.

Maruyama K and Hartl DL (1991) Evidence for interspecific transfer of the transposable element mariner between Drosophila and Zaprionus. J Mol Evol 33:514-524.

Mata RA, Tidon R, Côrtes LG, De Marco P and Diniz-Filho JAF (2010) Invasive and flexible: Niche shift in the drosophilid Zaprionus indianus (Insecta, Diptera). Biol Invasions 12:1231-1249.

Mattos-Machado T, Solé-Cava AM, David JR and Bitner-Mathé BC (2005) Allozyme variability in an invasive drosophilid, Zaprionus indianus (Diptera, Drosophilidae): Comparison of a recently introduced Brazilian population with Old World populations. Ann Soc Entomol Fr 41:7-13.

Nardon C, Deceliere G, Loevenbruck C, Weiss M, Vieira C and Biémont C (2005) Is genome size influenced by colonization of new environments in dipteran species? Mol Ecol 14:869-878.

Okada T (1981) Oriental species, including New Guinea. In: Ashburner M, Carson HL and Thompson JN (eds) The Ge- netics and Biology of Drosophila. vol. 3a. Academic Press, New York, pp 261-289.

Okada T (1990) New taxonomic changes in the family Drosophilidae (Diptera). Jpn J Entomol 5:154.

Okada T and Carson HL (1983) The genera Phorticella DUDA and Zaprionus COQUILLETT (Diptera, Drosophilidae) of the Oriental region and New Guinea. Jpn J Entomol 51:539553.

Parkash R and Sharma S (1993) Cryptic genic variability in Zaprionus indianus populations. Drosophila Inf Serv 72:94-95.

Parkash R and Yadav JP (1993a) Geographical clinal variation at seven esterase encoding loci in Indian populations of Zaprionus indianus. Hereditas 119:161-173.

Parkash R and Yadav JP (1993b) Latitudinal clinal variation in Zaprionus indianus populations. Drosophila Inf Serv $72: 150-152$

Parkash R, Yadav JP and Vashist M (1994) Electrophoretic and cryptic genic variability in natural populations of Zaprionus indianus. Proc Indian Nat Sci Acad 60:75-82.

Pelandakis M and Solignac M (1993) Molecular phylogeny of Drosophila based on ribosomal RNA sequences. J Mol Evol 37:525-543.

Powell JR and De Salle R (1995) Drosophila molecular phylogenies and their uses. In: Hecht MK (ed) Evolutionary Biology. Plenum, New York, pp. 87-139.

Remsen J and De Salle R (1998) Character congruence of multiple data partitions and the origin of the Hawaiian Drosophilidae. Mol Phylogenet Evol 9:225-235.

Robe LJ, Valente VL, Budnik M and Loreto EL (2005) Molecular phylogeny of the subgenus Drosophila (Diptera, Drosophilidae) with an emphasis on Neotropical species and groups: A nuclear versus mitochondrial gene approach. Mol Phylogenet Evol 36:623-640.

Roy K, Jablonski D and Valentine JW (2002) Body size and invasion success in marine bivalves. Ecol Lett 5:163-167.

Russo CA, Takezaki N and Nei M (1995) Molecular phylogeny and divergence times of drosophilid species. Mol Biol Evol 12:391-404.

Santos JF, Rieger TT, Campos SRC, Nascimento ACC, Félix PT, Silva SVO and Freitas FMR (2003) Colonization of northeast region of Brazil by the drosophilid flies Drosophila malerkotliana and Zaprionus indianus, a new potential insect pest for Brazilian fruitculture. Drosophila Inf Serv 86:92-95.

Schmitz HJ, Valente VL and Hofmann PR (2007) Taxonomic survey of Drosophilidae (Diptera) from mangrove forests of Santa Catarina Island, southern Brazil. Neotrop Entomol 36:53-64.

Setta N and Carareto CMA (2005) Fitness components of a recently-established population of Zaprionus indianus (Diptera, Drosophilidae) in Brazil. Iheringia Sér Zool 95:47-51.

Shakoori AR and Butt U (1979) Effect of thioacetamide on the development of a drosophilid fly. 1. Morphological studies. Pakistan J Zool 11:315-328.

Silva NM, Fantinel CD, Valente VLS and Valiati VH (2005a) Population dynamics of the invasive species Zaprionus indianus (Gupta) (Diptera, Drosophilidae) in communities of drosophilids of Porto Alegre city, southern Brazil. Neotrop Entomol 34:363-374. 
Silva NM, Fantinel Cc, Valente VLS and Valiati VH (2005b) Ecology of colonizing populations of the fig fly Zaprionus indianus (Diptera, Drosophilidade) in Porto Alegre, southern Brazil. Iheringia Sér Zool 95:233-240.

Soto I, Corio C, Fanara JJ and Hasson E (2006) First record of Zaprionus indianus Gupta 1970 (Diptera, Drosophilidae) in Argentina. Drosophila Inf Serv 89:13-14.

Souza Filho MF, de Prestes DAO, Sato ME and Raga A (2000) Host plants of Zaprionus indianus in the state of São Paulo, Brazil. International Congress of Entomology, Foz de Iguaçu, Brazil, pp 294.

Stalker HD (1980) Chromosomes studies in wild population of Drosophila melanogaster. II. Relationships of inversion frequencies to latitude, season, wing loading and flight activity. Genetics 95:211-223.

Stein CP, Teixeira EP and Novo JPS (2003) Aspectos biológicos da mosca do figo, Zaprionus indianus Gupta, 1970 (Diptera, Drosophilidae). Entomotropica 18:219-221.

Tatarenkov A, Kwiatowski J, Skarecky D, Barrio E and Ayala FJ (1999) On the evolution of Dopa decarboxylase (Ddc) and Drosophila systematics. J Mol Evol 48:445-462.

Thomas RH and Hunt JA (1993) Phylogenetic relationships in Drosophila: A conflict between molecular and morphological data. Mol Biol Evol 10:362-374.

Throckmorton LH (1962) Problem of phylogeny in the genus Drosophila. Univ Texas Publ 6205:207-344.

Throckmorton LH (1975) The phylogeny, ecology and geography of Drosophila. In: King RC (ed) Handbook of Genetics. Plenum Press, New York, pp 421-469.

Tidon R (2006) Relationships between drosophilids (Diptera, Drosophilidae) and the environment in two contrasting tropical vegetations. Biol J Linn Soc 87:233-248.

Tidon R, Leite DF and Leão BFD (2003) Impact of the colonization of Zaprionus indianus (Diptera, Drosophilidae) in different ecosystems of the Neotropical region: 2 years after the invasion. Biol Conserv 112:299-305.

Toni DC, Hofmann PRP and Valente VLS (2001) First register of Zaprionus indianus (Diptera, Drosophilidae) in the state of Santa Catarina, Brazil. Biotemas 14:71-85.

Tsacas L (1980) L'identité de Zaprionus vittiger Coquillett et revision des espèces afrotropicales affines. Bull Soc Entomol Fr 85:141-154.

Tsacas L (1985) Zaprionus indianus Gupta, 1970 nouveau nom pour le plus commun des Zaprionus africains (Diptera, Drosophilidae). Ann Soc Entomol Fr 21:343-344.

Tsacas L, Lachaise D and David J (1981) Composition and biogeography of the afrotropical drosophilid fauna. In: Ashburner M, Carson HLI and Thompson JN (eds) The Genetics and Biology of Drosophila. vol. 3a. Academic Press, London, pp 197-259.

Val FC and Sene FM (1980) A newly introduced Drosophila species in Brazil (Diptera, Drosophilidae). Pap Avulsos Zool 33:293-298.

van der Linde K, Steck GJ, Hibbard K, Birdsley JS, Alonso L and Mand Houle D (2006) First records of Zaprionus indianus (Diptera, Drosophilidae), a pest species on commercial fruits from Panama and the United States of America. Fla Entomol 89:402-403.

van der Linde K and Houle D (2008) A supertree analysis and literature review of the genus Drosophila and closely related genera (Diptera, Drosophilidae). Insect Syst Evol 39:241267.

Vidal NM, Ludwig A and Loreto EL (2009) Evolution of Tom, 297, 17.6 and rover retrotransposons in Drosophilidae species. Mol Genet Genomics 282:351-362.

Vilela CR (1999) Is Zaprionus indianus Gupta, 1970 (Diptera, Drosophilidae) currently colonizing the Neotropical region? Drosophila Inf Serv 82:37-39.

Vilela CR, Teixeira EP and Stein CP (2001) Mosca-africana do-figo, Zaprionus indianus (Diptera, Drosophilidae). In: Vilela E, Zucchi RA and Cantor F (eds) Histórico e Impacto das Pragas Introduzidas no Brasil. Editora Holos, São Paulo, pp 48-52.

Vogl C, Das A, Beaumont M, Mohanty S and Stephan W (2003) Population subdivision and molecular sequences variation: Theory and analyses of Drosophila ananassae data. Genetics 165:1385-1395.

Wheeler MR (1986) Additions to the catalog of the world's Drosophilidae. In: Ashburner M, Carson HL and Thompson Jr JN (eds) The Genetics and Biology of Drosophila. Academic Press, London, pp 395-409.

Wynn S and Toda MJ (1988) Drosophilidae (Diptera) in Burma. IV. The genus Zaprionus. Kontyû 56:843-851.

Yassin A (2007) A revision of the tumiditarsus group of the subgenus Drosophila and its relation to the genus Zaprionus. Drosophila Inf Serv 90:20-22.

Yassin A and David JR (2010) Revision of the Afrotropical species of Zaprionus (Diptera, Drosophilidae), with descriptions of two new species and notes on internal reproductive structures and immature stages. Zookeys 51:33-72.

Yassin A, Abou-Youssef AY, Bitner-Mathé BC, Capy P and David JR (2007) Developmental stress in wild-living drosophilids inferred from biometry: Metric and meristic traits react differently to heterogeneous environmental conditions. Ecol. Entomol 32:698-706.

Yassin A, Araripe LO, Capy P, Da Lage JL, Klaczko LB, Maisonhaute C, Ogereau D and David JR (2008a) Grafting the molecular phylogenetic tree with morphological branches to reconstruct the evolutionary history of the genus Zaprionus (Diptera, Drosophilidae). Mol Phylogenet Evol 47:903-915.

Yassin A, Capy P, Madi-Ravazzi L, Ogereau D and David JR (2008b) DNA barcode discovers two cryptic species and two geographical radiations in the invasive drosophilid Zaprionus indianus. Mol Ecol Notes 8:491-501.

Yassin A, Borai F, Capy P, David JR, Elias E, Riad SA, Shalaby HG, Serour S and Abou-Youssef AY (2009a) Evolutionary genetics of Zaprionus. II. Mitochondrial DNA and chromosomal variation of the invasive drosophilidae Zaprionus indianus in Egypt. Mitochondrial DNA 20:34-40.

Yassin A, David JR and Bitner-Mathé BC (2009b) Phenotypic variability of natural populations of an invasive drosophilid, Zaprionus indianus, on different continents: Comparison of wild-living and laboratory-grown flies. C R Biol 332:898908.

Yoshiyama M, Tu Z, Kainoh Y, Honda H, Shono T and Kimura K (2001) Possible horizontal transfer of a transposable element from host to parasitoid. Mol Biol Evol 18:1952-1958. 


\section{Internet Resources}

França FMC and Gondin RS (1999) Rede da irrigação - Documento $\mathrm{n}^{\mathrm{o}} 1$ (Mercado de Frutas e Hortaliças), http://www.bnb.gov.br/content/Aplicacao/ETENE/Rede Irrigacao/Docs/Fruticultura $\% 20 \mathrm{I}-\% 20 \mathrm{Uma} \% 20 \mathrm{visao} \% 20 \mathrm{~g}$ eral\%20do\%20mercado.PDF (April 29, 2007).

IBRAF (Instituto Brasileiro de Frutas) (2000-2001), http://www.ibraf.org.br/x-es/pdf/t-esta_cijd.pdf (April 29, 2007).

Ministério de Relações Exteriores (MRE) (2007), http://www.mre.gov.br/index.php?option = com con- tent\&task $=$ category $\&$ sectionid $=5 \&$ id $=11 \&$ Itemid $=557$ (April 29, 2007).

Ministério do

Desenvolvimento

(2007), http://www.desenvolvimento.gov.br/arquivo/secex/bartecn icas/barnaotarifadas/ africasul.pdf (April 29, 2007).

Stein CP (2000) Mosca do figo Zaprionus indianus, http://www.iac.br/ cenfit/artigos/zaprionus/index/htm (March 15, 2000).

Associate Editor: Louis Bernard Klaczko

License information: This is an open-access article distributed under the terms of the Creative Commons Attribution License, which permits unrestricted use, distribution, and reproduction in any medium, provided the original work is properly cited. 